88

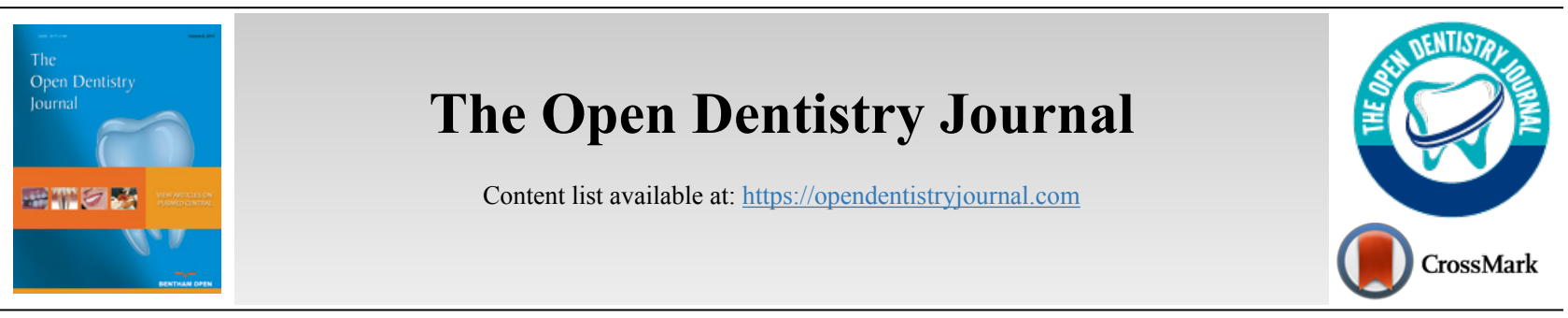

RESEARCH ARTICLE

\title{
Development and Validation of the Greek version of the Early Childhood Oral Health Impact Scale (ECOHIS)
}

\author{
Konstantina Taoufik ${ }^{1, *}$, Kimon Divaris ${ }^{2,3}$, Katerina Kavvadia ${ }^{4}$, Haroula Koletsi-Kounari ${ }^{1}$ and Argy Polychronopoulou ${ }^{1}$ \\ ${ }^{\prime}$ Department of Community and Preventive Dentistry, School of Dentistry, National and Kapodistrian University of Athens, Athens, Greece \\ ${ }^{2}$ Department of Pediatric Dentistry, School of Dentistry, University of North Carolina-Chapel Hill, Chapel Hill, NC, United States \\ ${ }^{3}$ Department of Epidemiology, UNC Gillings School of Global Public Health, University of North Carolina-Chapel Hill, Chapel Hill, NC, United \\ States \\ ${ }^{4}$ Department of Pediatric Dentistry, School of Dentistry, University of Louisville, Kentucky, KY, United States
}

\begin{abstract}
:
Background:

The oral health of preschool-age children can affect their quality of life (QoL) as well their families. The Early Childhood Oral Health Impact Scale (ECOHIS) is a reliable instrument that has been used to assess the impact of oral health problems and their treatment on the QoL of preschool-age children and their families'.

Objective:

To report the development, evaluation and psychometric properties of the Greek version of ECOHIS (Gr-ECOHIS).

Methods:

Participants of this cross-sectional study were 176 mothers and their young (aged 25-71 months) children, patients of a private pediatric dental practice. During a structured interview, they completed a questionnaire, including a translated, Greek language version of the ECOHIS. Data on children's oral health were obtained via clinical examinations. The psychometric properties of Gr-ECOHIS evaluated were reliability (internal and test-retest) and construct (convergent and discriminant) validity. Test-retest reliability was determined in an independent sample of 20 mother-child dyads, who completed the Gr-ECOHIS twice within a two-week interval.

Results:

The scale showed excellent internal consistency (Cronbach's alpha=0.85) and test-retest reliability (Intraclass Correlation Coefficient $=0.97)$. GrECOHIS showed a strong correlation with dental caries (Spearman's $r h o=0.62, \mathrm{p}<0.0005$ ) and dental treatment needs. Gr-ECOHIS was also positively associated with dental knowledge, health literacy and parental oral health-related QoL.

Conclusion

The Gr-ECOHIS is a psychometrically reliable and valid Greek language QoL instrument, which demonstrated significant associations with clinical and parent-reported measures of early childhood oral health. As such, it can be used to measure oral health-related QoL among preschoolage children in clinical and public health settings.
\end{abstract}

Keywords: Early Childhood Oral Health Impact Scale, ECOHIS, Validity, Psychometric properties, Oral health, Preschool age children.

\begin{tabular}{|l|l|l|r|}
\hline Article History & Received: December 01, 2019 & Revised: January 21, 2020 & Accepted: February 02, 2020
\end{tabular}

\section{INTRODUCTION}

Early childhood caries is a significant and persistent health issue for preschool-age children, conferring severe impacts on their development, as well as their and their families' lives [1]. Measurement of these impacts requires the use of instruments that capture a broad spectrum of events, extending beyond the traditional, clinically defined indices of dental caries burden
[2]. The first instrument used to assess oral health-related Quality of Life (QoL) of preschool-age children was introduced by Filstrup and colleagues in 2003 in the context of a prospective intervention study among 69 children [3], whereas a validated instrument was introduced in 2007 [4].

Measurement of subjective oral health in the preschool-age child population is challenging for several reasons. First, 
preschool-age children cannot provide accurate answers themselves-abstract thinking and the recall of specific events beyond 24 hours are acquired at the age of 6 or older $[5,6]$. Moreover, children's oral health problems and their treatment may affect their families' lives; children's pain experience, inability to properly feed, missing school, and parents having to miss work are some of these impacts on daily life. Finally, additional domains of possible impact include financial and psychological consequences on parents [7 - 11].

The Early Childhood Oral Health Impact Scale (ECOHIS) was developed in 2007 as an instrument designed to assess the oral health-related QoL of preschool-age children. The instrument is completed by children's caregivers and includes a child and a family impact section. It is a short and easy to use the instrument, with good validity and reliability [12]. The ECOHIS has been translated and tested in many languages [13 - 27]. All published versions have demonstrated good psychometric properties. The ECOHIS can be used for the identification of the characteristics (individual, environmental, sociodemographic) that impact on oral health-related QoL, changes due to treatment or intervention, as well as to screen and identify those who are in need for intervention. To date, there has been no reported adaptation and validation of the scale in the Greek language. To address this gap, we undertook this study aiming to develop and evaluate the psychometric properties of the Greek version of the ECOHIS (Gr-ECOHIS).

\section{MATERIALS AND METHODS}

\subsection{Study Population}

The sample selection strategy, rationale and specific procedures for this cross-sectional study have been previously detailed as part of the development and validation of a Greek Oral Health Literacy instrument (GROHL) [28]. Briefly, for the present study, we targeted an analytical sample size in the range of 10-15 participants per item, as the general guidance for sample size requirements of instrument and validation studies is reported to range between 2 and 20 [29]. The new index contains 13 items and thus, our final study sample of 176 was at the upper end of that range (i.e., we included $>13$ participants per item). Moreover, previous ECOHIS adaptation and validation studies were done on similarly-sized samples, ranging between 111 and 295 participants [12, 14, 19, 26]. Specifically, our study's participants were mothers of preschool-age children who attended two private pediatric dental clinics in Athens, Greece, for routine care. The inclusion criteria were mothers' self-reported ability to speak, understand, and write in the Greek language and children's age (24-71 months). Eligible participants were excluded if their children presented with general health problems that might influence their QoL. These included medical conditions and treatments that could impact oral health including but not limited to cancer, intellectual and motor disability, salivary gland disorders, and HIV infection. Out of 200 screened individuals, 10 were found to be ineligible and 14 decided not

\footnotetext{
* Address correspondence to this author at the Department of Community and Preventive Dentistry, School of Dentistry, National and Kapodistrian University of Athens, Thivon 2Str., Goudi, 11527, Athens, Greece.,
}

Tel: (+30) 210-746-1289, (+30) 694-455-3666; E-mail: ktaoufik@dent.uoa.gr to participate in the study (participation rate $=93 \%$ ). An independent sample of 20 adults was used for the evaluation of the instrument's test-retest reliability over a two-week period, with the same inclusion/exclusion criteria. The study received ethics approval from the institutional review board of the Dental School of National and Kapodistrian University of Athens, Greece (251A/31-07-2014) and all participants provided a signed, informed consent.

\subsection{Data Collection, Instruments and Measures}

Data were collected using a structured questionnaire administered via interview, as well as a dental chart review. Interviews lasted approximately 30 minutes and were conducted by one investigator (KT) in settings and times convenient for the participants. The questionnaire included items regarding socio-demographic characteristics, health status and behaviors, oral health knowledge, and oral healthrelated QoL. Oral health literacy was measured with a Greeklanguage, 20-item, word recognition and comprehension test, the GrOHL-20 [28]. Information on participants' health status and health behaviors were derived from questions regarding overall health and oral health, dental visits and oral hygiene practices. More specifically, the participants answered 2 selfrated oral and general health questions with 5 possible answers (excellent, very good, good, fair, poor), when their last dental visit occurred and why. Oral health knowledge was evaluated with a test of 16 statements and each participant was asked to agree or disagree, while a third option of "don't know" was also possible. Correct answers were scored with 1 and incorrect or don't know scored with 0. Oral health-related QoL was measured with the Greek Oral Health Impact Profile [30]. Children's oral health status was assessed by parent questions and via a clinical examination. Clinical oral examinations were performed by a trained and calibrated examiner and dental caries burden (dmft) was measured using the recommended WHO criteria for visual assessment of dental caries [31]. Although no calibration took place for the purposes of this study, all clinical data and restorative treatment need assessments were ascertained by a single, experienced clinician examiner and specialist in Pediatric Dentistry. Of note, the clinical examiner (first and corresponding author of the present manuscript) was previously trained and calibrated for research oral clinical examinations of preschool-age children of another clinical research project.

The ECOHIS includes 13 questions in two domains: the child (CIS; 9 items) and the family (FIS; 4 items) sections. Answers are given on a 5-point frequency scale ranging between never and very often and include an option "I don't know" [12]. Thus, the ECOHIS total score can take values ranging between 0 and 52, with small values denoting few oral health impacts and better QoL. For the purposes of this study, the ECOHIS was translated into Greek using a forwardbackward translation approach [32]. First, the original English version was translated in Greek by a native Greek speaker and the translated version was examined by a bilingual health expert. Then two dental academicians and investigators who were proficient in English produced a back-translation of the initial Greek instrument into English. This final version was also screened and verified in terms of language and with an 
independent native speaker and translator.

\subsection{Analytical Approach}

Data analysis was conducted with Stata 16.0 (StataCorp LP, College Station, TX). We generated initial descriptive statistics (e.g., frequencies, proportions, means, standard deviations, medians, ranges), and then conducted analyses of variance (e.g., ANOVA) and linear regression modeling. The normality of data distribution was determined via a combined skewness and kurtosis test [33]. The Gr-ECOHIS construct reliability (i.e., internal consistency) was examined using Cronbach's alpha, and test-retest reliability was assessed using the Intraclass Correlation Coefficient (ICC). Convergent validity was tested against functional Health Literacy Screening (HLS) items, Dental Knowledge (DK), Oral Health Behaviors (OHBs), Oral Health-related QoL (OHIP-14 index), as well as self-reported oral and general health status. Predictive validity was assessed using children's parentreported and objectively measured (i.e., clinically ascertained) oral health and treatment needs. A Bonferroni correction for multiple testing correction was applied-thus, to correct for 31 independent tests, the critical p-value for statistical significance was set to $0.05 / 31=0.0016$.

\section{RESULTS}

The children's mean age was 4.3 (range $=2.1-5.9$ ) years. The mean Gr-ECOHIS score was 3.4 with a range of $0-27$. Half of the participants' score was 0 , indicating a frankly skewed, non-normal distribution (D' Agostino combined skewness and kurtosis test, $\mathrm{p}<0.05)$. The scale showed good internal consistency (Cronbach's alpha $=0.85$ ) and an excellent test-retest reliability $(\mathrm{ICC}=0.97 ; 95 \% \mathrm{CI}=0.93-0.99)$ (Fig. 1). In terms of the instrument's sub-scales, the Gr-ECOHIS child domain had alpha $=0.82$; mean $=1.4$, range $=0-17$ and the family domain had alpha $=0.78$, mean $=1.9$, range $=0-11$ (Table 1).

The sociodemographic characteristics of the participating mothers and the corresponding distribution of Gr-ECOHIS scores are presented in Table 2. Respondents had high educational status, with half of them being university graduates or more. Their mean age of 38 years, virtually all were married and Greek-born. Their health literacy (GROHL-20) scores were normally distributed $($ mean $=11.3, \mathrm{SD}=3.8$, range $=1-20)$. No important associations were noted between mothers' characteristics and Gr-ECOHIS scores, with the exception of having three children or more being associated with higher scores $(p=0.0008)$. Similarly, no important associations were noted between Gr-ECOHIS and maternal health/oral health statuses and dental behaviors (Table 3 ).

Contrary, strong associations were found between clinical and self-reported measures of oral disease, as presented in Table 4. Clinical assessments of needs for restorations, pulp therapy, or extraction were significantly associated with higher Gr-ECOHIS scores (all $\mathrm{p}<0.0005$ ). Similarly, worse parental reports of children's oral health status were associated with higher scores, e.g., 'fair-poor' child oral health status: mean= $8.4(\mathrm{SD}=7.1)$ versus 'very good' mean $=1.7(\mathrm{SD}=3.4)$ versus 'excellent' mean=0.7 $(\mathrm{SD}=1.9)$.
As expected, Gr-ECOHIS scores were also strongly and positively associated with dental caries burden, as determined clinically via the dmft index (Table 5). The distribution of $\mathrm{dmft}$ scores (mean=2.3, $\mathrm{SD}=3.3$, range $=0-13$ ) and their corresponding association with Gr-ECOHIS scores are illustrated in a scatter plot with an overlaid local polynomial smoothing function (Fig. 2). Both the child and the family domain scores were significantly associated with $\mathrm{dmft}$; however, the family domain had the strongest estimate of association. Gr-ECOHIS scores were also positively associated with mothers' oral health-related QoL. Weaker and non-statistically significant associations were found with mothers' dental knowledge and health literacy.

\section{DISCUSSION}

To date, no published data on Greek preschool-age children's oral health-related QoL exist-arguably, because no instrument can assess it. Here, to address this knowledge gap, we report the development and psychometric properties of GrECOHIS. The new instrument can be used for research and public health purposes, as well as for screening for unmet dental needs, and oral health-related child and family impacts $[2,34,35]$. We found that Gr-ECOHIS has good internal consistency and excellent test-retest reliability, similar to the results reported for other language versions of the ECOHIS [13 - 27]. We also found that the index had favorable convergent validity, which we estimated against parents' reports of oral health status, similar to the evaluation of the Brazilian BECOHIS [17]. This is an important point, because children's clinically-determined oral health status may not be evident to parents, and may not confer impacts on their QoL unless it is associated with pain, discomfort, functional or esthetic problems. Discriminant validity was demonstrated via the scale's strong association with dental caries burden and objectively (i.e., clinically) determined dental treatment needs.

The results of the present study compare favorably with those of previous reports of similar instruments' development and adaptations. For example, the scale's internal consistency (alpha of 0.85) is within the range of previous ECOHIS adaptations, including the French [13] (0.82), Farsi [15] (0.93), Spanish [18] (0.87), Lithuanian [20] (0.87), Turkish [16] (0.93), Malay [23] (0.83), Kiswahili and Luganda [21] (0.84) versions. Similar findings were also reported for test-retest reliability as well as the child and family sub-scales. Of note, the present study's findings of GrECOHIS' strong association with clinically-determined oral health status (i.e., dmft index) are concordant with previously published studies of international adaptations of ECOHIS [16, 19, 20, 22, 23]. In fact, López Ramos and colleagues [22] reported a similar correlation coefficient between $\mathrm{dmft}$ and ECOHIS scores (Spearman's rho 0.56 vs. 0.62 in the present study). It is important to note that although both the child and the family domain scores were significantly associated with $\mathrm{dmft}$, in our sample the overall association was driven predominantly by the family domain, i.e., family domain, rho $=0.69$ versus child domain, $r h o=0.43$. This is not surprising, in light of a recent study that found ECOHIS, and specifically, its family impact subscale is the highest-quality instrument for assessing oral health-related QoL among children [36]. Overall, these 
findings are consistent with the notion of childhood dental caries and its treatment affecting and impacting the family as a unit [2].

It must be acknowledged that the specific associations and correlations reported here, albeit statistically robust (i.e., the correlation between $\mathrm{dmft}$ and GrECOHIS, $r h o=0.62$ ) are not necessarily clinically interpretable or significant. We would argue even high magnitude correlations are not always clinically significant, as these associations must be placed in context and evaluated for specific applications. Our effort here does revolve around making inferences regarding clinical inferences from these or other correlation coefficients. Our goal was to perform 'standard' psychometric association tests between a wide array of instruments, variables and constructs to understand the patterns of association of the new instrument with other, well-established measures. The extent to which these associations or correlations translate to clinical significance is a topic that is beyond the scope of our investigation. We suggest that, now that the instrument is developed and validated, future studies can examine its sensitivity and responsiveness to clinical changes, similar to other QoL instruments [37].

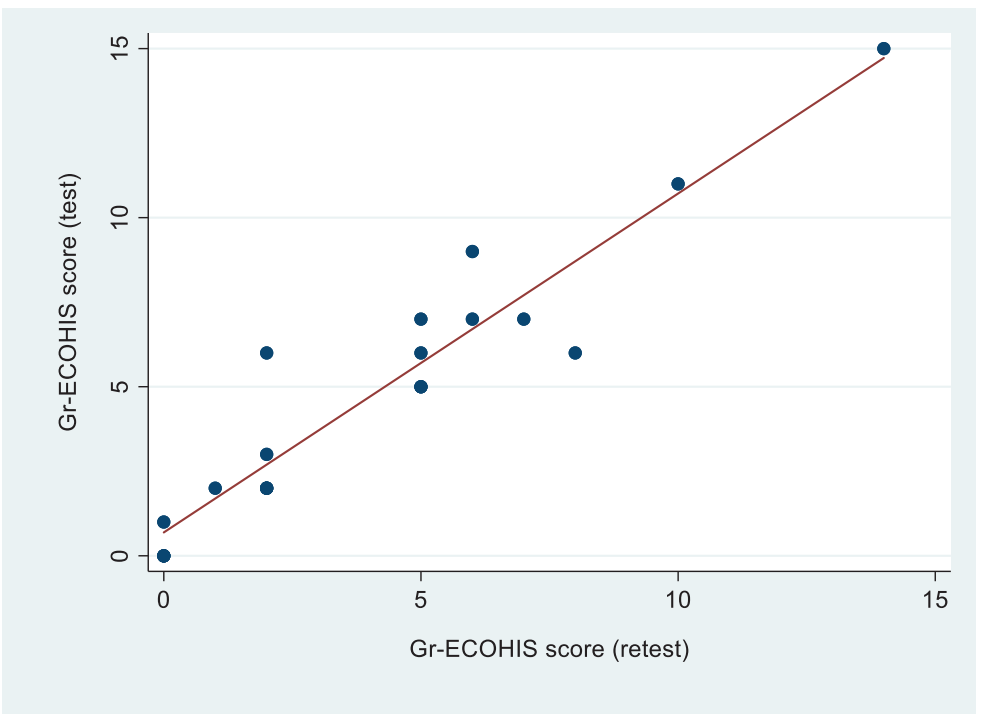

Fig. (1). Results of the GrECOHIS test-retest reliability assessment, illustrating the correspondence between first (test) and second (re-rest, two weeks later) administration. A high degree of agreement was found (Intraclass correlation coefficient $=0.97$; 95\% confidence interval=0.93-0.99).

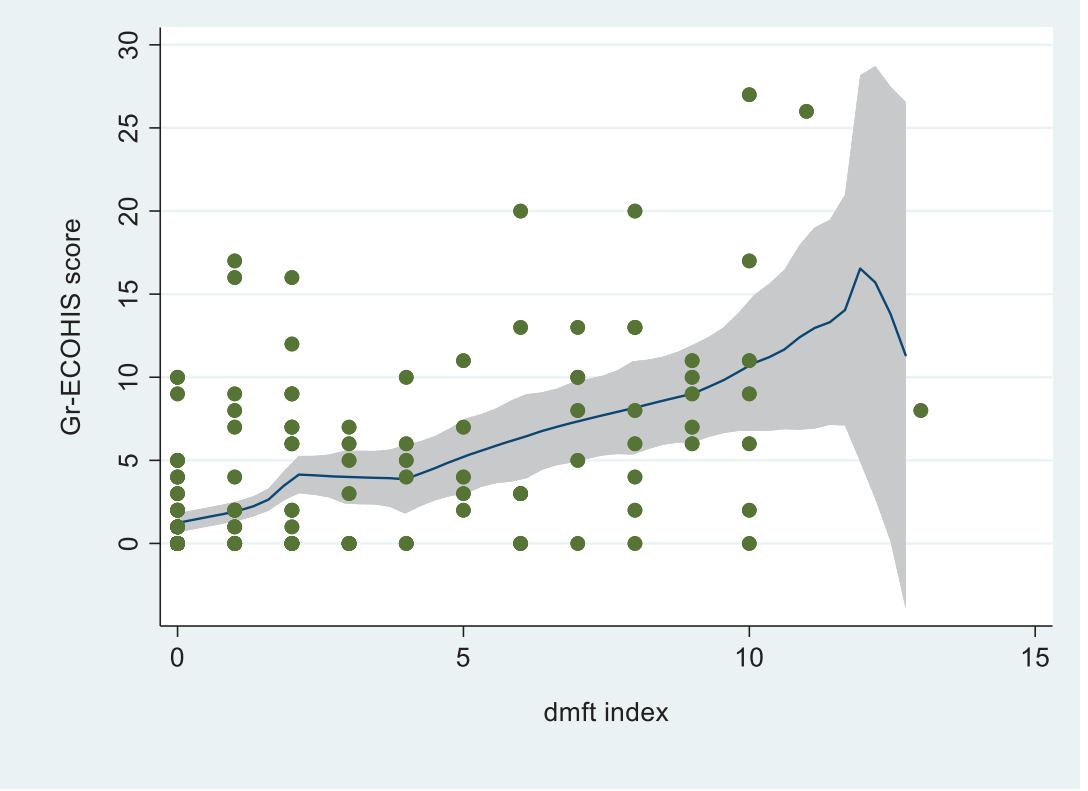

Fig. (2). Association between Gr-ECOHIS scores and dmft index among the 176 child study participants illustrated by a local polynomial smoothing function (blue line) and corresponding 95\% confidence intervals (grey shaded area). 
Table 1. Distribution of responses to the $13 \mathrm{Gr}-\mathrm{ECOHIS}$ items, according to its child and the family domains, among the 176 study participants.

\begin{tabular}{|l|c|c|}
\hline & $\begin{array}{c}\text { Never or hardly } \\
\text { ever, } \mathbf{n}(\%)\end{array}$ & $\begin{array}{c}\text { Occasionally, often, or } \\
\text { very often, } \mathbf{( \% )}\end{array}$ \\
\hline Child impacts & & $23(13)$ \\
\hline How often has your child had pain in the teeth, mouth or jaws & $153(87)$ & $12(7)$ \\
\hline How often has your child ....because of dental problems or dental treatments? & & $8(5)$ \\
\hline had difficulty drinking hot or cold beverages & $164(93)$ & $9(5)$ \\
\hline had difficulty eating some foods & $168(95)$ & $3(2)$ \\
\hline had difficulty pronouncing any words & $167(95)$ & $5(3)$ \\
\hline missed preschool, daycare or school & $173(98)$ & $13(7)$ \\
\hline had trouble sleeping & $171(97)$ & $4(2)$ \\
\hline been irritable or frustrated & $163(93)$ & $1(1)$ \\
\hline avoided smiling or laughing & $172(98)$ & \\
\hline avoided talking & $175(99)$ & \\
\hline \multicolumn{1}{|c|}{ Famild sub-scale $(a l p h a=0.82)$, mean=1.5 (SD=3.0), range $=0-17$} & \\
\hline Family impacts & & \\
\hline $\begin{array}{l}\text { How often have you or another family member.....because of your child's dental problems or } \\
\text { treatments? }\end{array}$ & & \\
\hline been upset & $142(81)$ & $34(19)$ \\
\hline felt guilty & $134(76)$ & $42(24)$ \\
\hline taken time off from work & $170(97)$ & $6(3)$ \\
\hline $\begin{array}{l}\text { How often has your child had dental problems or dental treatments that had a financial impact on } \\
\text { your family? }\end{array}$ & $137(78)$ & $39(22)$ \\
\hline & & \\
\hline
\end{tabular}

Table 2. Parents' sociodemographic characteristics and their children's oral health-related quality of life (Gr-ECOHIS) estimates, among the 176 study parent-child dyads.

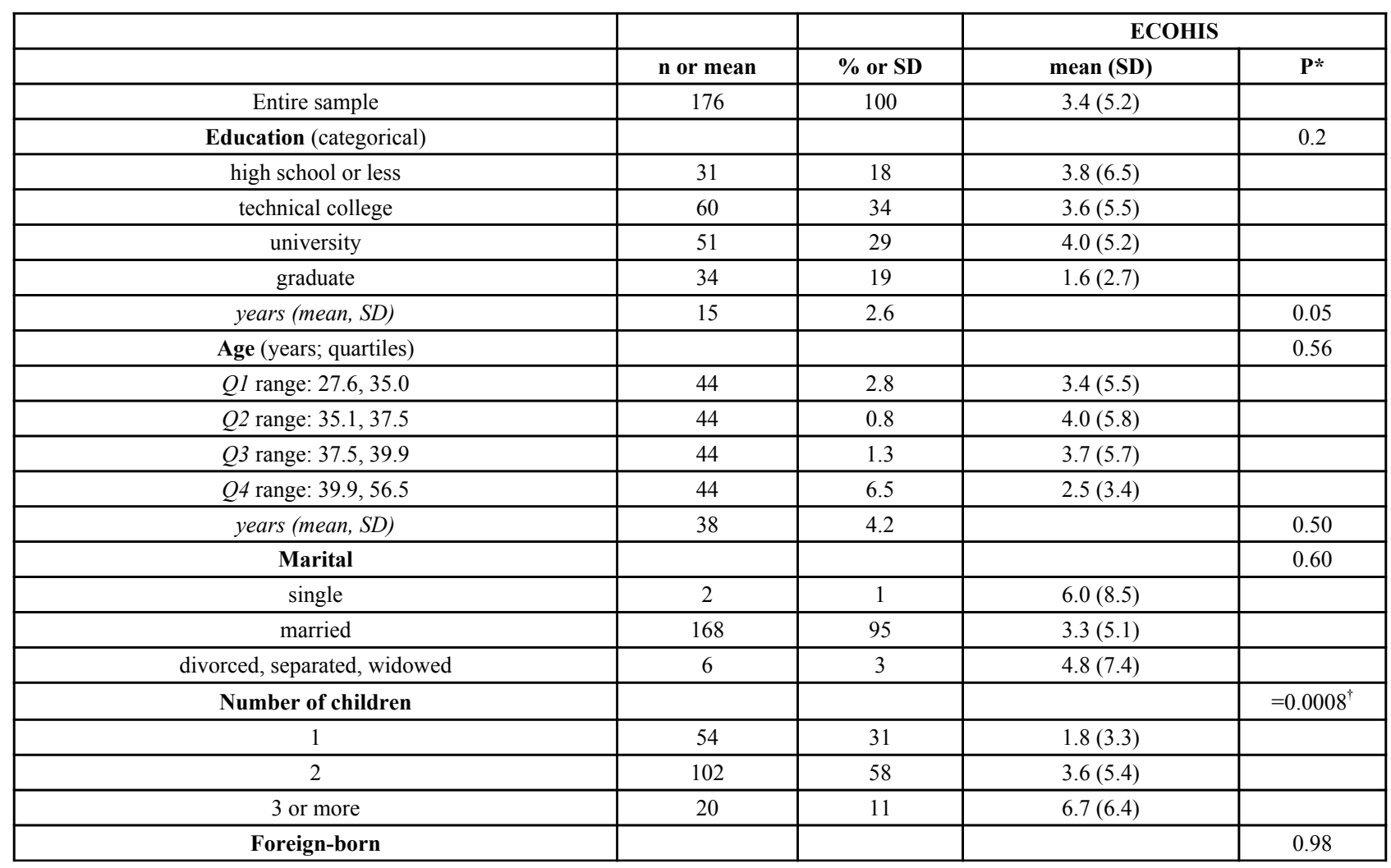


(Table 2) contd.....

\begin{tabular}{|c|c|c|c|c|}
\hline & & & \multicolumn{2}{|c|}{ ECOHIS } \\
\hline & n or mean & $\%$ or SD & mean (SD) & $\mathbf{P *}$ \\
\hline no & 167 & 95 & $3.4(5.2)$ & \\
\hline yes & 9 & 5 & $3.3(4.5)$ & \\
\hline
\end{tabular}

SD, standard deviation *derived from analyses of variance (ANOVA) or linear regression $\dagger$ statistically significant after Bonferroni correction for study-wide multiple testing ( 31 independent tests).

Table 3. Parents' general and oral health status and dental care seeking attitudes and their association with their children's oral health-related quality of life (Gr-ECOHIS scores) among the 176 study parent-child dyads

\begin{tabular}{|c|c|c|c|c|}
\hline & & \multicolumn{3}{|c|}{ GR-ECOHIS } \\
\hline & $\mathbf{n}$ & col. $\%$ & mean (SD) & $\mathbf{P}^{*}$ \\
\hline Entire sample & 176 & 100 & $3.4(5.2)$ & \\
\hline Parent's general health status & & & & 0.01 \\
\hline Excellent & 19 & 8 & $2.2(3.3)$ & \\
\hline Very good & 98 & 56 & $2.6(4.4)$ & \\
\hline Good & 45 & 26 & $5.3(6.8)$ & \\
\hline Fair-poor & 14 & 11 & $4.4(5.3)$ & \\
\hline Parent's oral health status & & & & 0.28 \\
\hline Excellent & 3 & 2 & $3.0(5.2)$ & \\
\hline Very good & 46 & 26 & $2.1(4.8)$ & \\
\hline Good & 76 & 43 & $3.7(5.1)$ & \\
\hline Fair-poor & 51 & 29 & $4.0(5.6)$ & \\
\hline Last dental visit timing & & & & 0.63 \\
\hline$<12$ months ago & 114 & 65 & $3.4(5.0)$ & \\
\hline 12-23 months ago & 41 & 23 & $4.0(6.5)$ & \\
\hline $2-5$ years ago & 14 & 8 & $2.8(3.5)$ & \\
\hline$>5$ years go & 5 & 3 & $1.0(1.2)$ & \\
\hline don't remember & 2 & 1 & & \\
\hline Last dental visit reason & & & & 0.59 \\
\hline routine & 105 & 60 & $3.1(5.3)$ & \\
\hline restorative & 43 & 24 & $4.0(4.8)$ & \\
\hline problem/pain & 28 & 16 & $3.7(5.5)$ & \\
\hline Frequency of dental visits & & & & 0.81 \\
\hline every 6 months & 41 & 23 & $3.0(4.7)$ & \\
\hline every year & 79 & 45 & $3.3(5.3)$ & \\
\hline every $1-2$ years & 29 & 17 & $4.2(5.6)$ & \\
\hline Only when there is a problem & 24 & 14 & $3.2(5.6)$ & \\
\hline don't remember & 3 & 2 & & \\
\hline
\end{tabular}

SD, standard deviation *derived from analyses of variance (ANOVA).

Table 4. Children's clinically-assessed restorative dental treatment needs, parental reports of their oral health status,estimates of their oral health-related quality of life (Gr-ECOHIS scores).

\begin{tabular}{|c|c|c|c|c|}
\hline & & & \multicolumn{2}{|c|}{ GR-ECOHI } \\
\hline & $\mathbf{n}$ & col. $\%$ & mean (SD) & \multicolumn{1}{|c|}{ P* } \\
\hline Entire sample & 176 & 100 & $3.4(5.2)$ & \\
\hline Clinical measures & & & & $<0.0005^{\dagger}$ \\
\hline Requires an intra-coronal restoration & & & & \\
\hline No & 88 & 50 & $0.8(2.1)$ & $<0.0005^{\dagger}$ \\
\hline Yes & 88 & 50 & $6.0(6.1)$ & \\
\hline Requires pulp therapy & & & & \\
\hline Yes & 144 & 82 & $2.4(4.3)$ & \\
\hline Requires a tooth extraction & 32 & 18 & $7.7(6.5)$ & $<0.0005^{\dagger}$ \\
\hline
\end{tabular}


(Table 4) contd....

\begin{tabular}{|c|c|c|c|}
\hline & & \multicolumn{2}{|c|}{ GR-ECOHIS } \\
\hline & P & col. \% & mean (SD) \\
\hline No & 169 & 96 & $3.1(4.8)$ \\
\hline Yes & 7 & 4 & $11.3(8.3)$ \\
\hline Parental report of child's oral health status & & & \\
\hline Excellent & 24 & 14 & $<0.0005^{\dagger}$ \\
\hline Very good & 54 & 31 & $0.7(1.9)$ \\
\hline Good & 62 & 35 & $1.7(3.4)$ \\
\hline Fair-poor & 36 & 20 & $3.0(4.1)$ \\
\hline
\end{tabular}

$\mathrm{SD}$, standard deviation *derived from analyses t-tests $\uparrow$ statistically significant after Bonferroni correction for study-wide multiple testing (31 independent tests).

Table 5. Spearman rank correlations of children's oral health-related quality of life (Gr-ECOHIS score) with parents' dental knowledge, OHRQoL (OHIP-14 index) severity of impacts, functional health literacy screener, and children's dental caries burden (decayed, missing due to caries and restored teeth index) among the 176 study parent-child dyads.

\begin{tabular}{|c|c|c|c|c|c|c|}
\hline & Entire scale & \multicolumn{2}{|c|}{ Child domain } & Family domain \\
\hline & rho & P & rho & P & rho & P \\
\hline Oral health literacy (GrOHL-20 index) & -0.05 & 0.52 & -0.08 & 0.33 & -0.06 & 0.47 \\
\hline Functional health literacy index & -0.23 & 0.004 & -0.22 & 0.006 & -0.19 & 0.02 \\
\hline Dental knowledge index & -0.16 & 0.05 & -0.16 & 0.04 & -0.11 & 0.16 \\
\hline Oral health-related quality of life (OHIP severity index) & 0.29 & 0.0003 & 0.23 & 0.004 & 0.25 & 0.002 \\
\hline Dental caries burden (dmft index) & 0.62 & $<0.0005^{\dagger}$ & 0.43 & $<0.0005^{\dagger}$ & 0.69 & $<0.0005^{\dagger}$ \\
\hline
\end{tabular}

†statistically significant after Bonferroni correction for study-wide multiple testing (31 independent tests).

A limitation of this study is that it included only female respondents-this not uncommon for a study investigating parental perceptions of their children's oral health. Moreover, these mothers were of relatively high education and were recruited from private dental clinics; i.e., these families were seeking restorative or preventive dental care for their children, a characteristic that places them at a higher level of dental use compared to other families that would seek emergency or no dental care at all. One might expect that worse oral health and more QoL impacts would be found among individuals of lower socioeconomic status, not seeking regular dental care, or with higher levels of dental disease. Thus, we recommended that the performance of the new instrument is also tested in the future among non-care seeking families of young children. Future studies may also investigate the equivalence of GrECOHIS with the original ECOHIS, by administering them to perfectly bilingual caregivers of young children. Such investigations, as well as ancillary qualitative studies, may also shed led on any cross-cultural adaptation issues, as this issue was not formally explored as part of this instrument development and assessment study.

\section{CONCLUSION}

The Greek version of the ECOHIS has favorable psychometric properties and can be considered as a valid and reliable measure of oral health-related QoL in preschool-age children. It is a brief and easy-to-use instrument that can be used in clinical and public health settings to distinguish those with worse oral health and most oral health-related QoL impacts, likely in need of dental care. Upon further testing and validation, the scale may also be used in studies evaluating the effects of various clinical and public health interventions on subjective oral health in this population group.

\section{LIST OF ABBREVIATIONS}

$$
\begin{array}{ll}
\text { ECOHIS } & \text { Early Childhood Oral Health Impact Scale } \\
\text { Gr-ECOHIS }= & \text { Greek version of Early Childhood Oral Health } \\
& \text { Impact Scale } \\
\text { GROHL-20 }= & \text { Greek language Oral Health Literacy Instrument } \\
\text { dmft } & \text { decayed, missing due to caries and filled teeth } \\
& \text { index } \\
\text { WHO } & \text { World Health Organization } \\
\text { CIS } & \text { Child Impact Scale } \\
\text { FIS } & \text { Family Impact Scale } \\
\text { ICC } & \text { Intraclass Correlation Coefficient } \\
\text { HLS } & =\text { Functional Health Literacy Screening } \\
\text { DK } & =\text { Dental Knowledge } \\
\text { OHBs } & =\text { Oral Health Behaviors } \\
\text { OHRQoL } & \text { Oral Health-Related Quality of Life } \\
\text { OHIP } & =\text { Oral Health Impact Profile } \\
\text { B-ECOHIS }= & \text { Brazilian version of the Early Childhood Oral } \\
& \text { Health Impact Scale }
\end{array}
$$

\section{ETHICS APPROVAL AND CONSENT TO PARTI-} CIPATE

The study received approval from the Ethics Committee of the School of Dentistry, National and Kapodistrian University of Athens, Greece (251A/31-07-2014). 


\section{HUMAN AND ANIMAL RIGHTS}

Not applicable.

\section{CONSENT FOR PUBLICATION}

All participants provided signed, informed consent.

\section{AVAILABILITY OF DATA AND MATERIALS}

The data used to generate and support the findings of this study are available from the corresponding author [K.T] upon request.

\section{FUNDING}

None.

\section{CONFLICT OF INTEREST}

The authors declare that they have no conflict of interest, financial or otherwise.

\section{ACKNOWLEDGEMENTS}

KT contributed to the design of the study, collection of the data, management of the data, participated in manuscript preparation. KD contributed to the conception and design of the study, conducted the data analysis, assisted with the interpretation of the results, and writing of the manuscript. KK participated in the design of the study and revised the manuscript critically for intellectual content. HKK participated in the design of the study and revised the manuscript critically for intellectual content. AP contributed to the conception and design of the study, was the lead coordinator of the study, participated in manuscript preparation. All authors read and approved the final version of the manuscript prior to submission.

\section{REFERENCES}

[1] Tinanoff N, Baez RJ, Diaz Guillory C, et al. Early childhood caries epidemiology, aetiology, risk assessment, societal burden, management, education, and policy: Global perspective. Int J Paediatr Dent 2019; 29(3): 238-48

[http://dx.doi.org/10.1111/ipd.12484] [PMID: 31099128]

[2] Casamassimo PS, Thikkurissy S, Edelstein BL, Maiorini E. Beyond the dmft: The human and economic cost of early childhood caries. J Am Dent Assoc 2009; 140(6): 650-7.

[http://dx.doi.org/10.14219/jada.archive.2009.0250] [PMID: 19491160]

[3] Filstrup SL, Briskie D, da Fonseca M, Lawrence L, Wandera A, Inglehart MR. Early childhood caries and quality of life: Child and parent perspectives. Pediatr Dent 2003; 25(5): 431-40. [PMID: 14649606]

[4] Grange A, Bekker H, Noyes J, Langley P. Adequacy of health-related quality of life measures in children under 5 years old: Systematic review. J Adv Nurs 2007; 59(3): 197-220.

[http://dx.doi.org/10.1111/j.1365-2648.2007.04333.x] [PMID: 17627625]

[5] Hetherington EM, Parke RD, Locke VO. Child psychology: A contemporary viewpoint. $5^{\text {th }}$ ed. New York: The McGrawHillCompanies 1999.

[6] Rebok G, Riley A, Forrest C, et al. Elementary school-aged children's reports of their health: A cognitive interviewing study. Qual Life Res 2001; 10(1): 59-70.

[http://dx.doi.org/10.1023/A:1016693417166] [PMID: 11508476]

[7] Acs G, Lodolini G, Kaminsky S, Cisneros GJ. Effect of nursing caries on body weight in a pediatric population. Pediatr Dent 1992; 14(5): 302-5.

[PMID: 1303533]
[8] Gift HC, Reisine ST, Larach DC. The social impact of dental problems and visits. Am J Public Health 1992; 82(12): 1663-8.

[http://dx.doi.org/10.2105/AJPH.82.12.1663] [PMID: 1456343]

[9] Ayhan H, Suskan E, Yildirim S. The effect of nursing or rampant caries on height, body weight and head circumference. J Clin Pediatr Dent 1996; 20(3): 209-12.

[PMID: 8634207]

[10] Vargas CM, Crall JJ, Schneider DA. Sociodemographic distribution of pediatric dental caries: NHANES III, 1988-1994. J Am Dent Assoc 1998; 129(9): 1229-38.

[http://dx.doi.org/10.14219/jada.archive.1998.0420] [PMID: 9766104]

[11] Casamassimo PS. Relationships between oral and systemic health. Pediatr Clin North Am 2000; 47(5): 1149-57.

[http://dx.doi.org/10.1016/S0031-3955(05)70261-3] [PMID: 11059353]

[12] Pahel BT, Rozier RG, Slade GD. Parental perceptions of children's oral health: The Early Childhood Oral Health Impact Scale (ECOHIS). Health Qual Life Outcomes 2007; 5: 6 . [http://dx.doi.org/10.1186/1477-7525-5-6] [PMID: 17263880]

[13] Li S, Veronneau J, Allison PJ. Validation of a French language version of the Early Childhood Oral Health Impact Scale (ECOHIS). Health Qual Life Outcomes 2008; 6: 9.

[http://dx.doi.org/10.1186/1477-7525-6-9] [PMID: 18211711]

[14] Lee GH, McGrath C, Yiu CK, King NM. Translation and validation of a Chinese language version of the Early Childhood Oral Health Impact Scale (ECOHIS). Int J Paediatr Dent 2009; 19(6): 399-405.

[http://dx.doi.org/10.1111/j.1365-263X.2009.01000.x] [PMID: 19811551]

[15] Jabarifar SE, Golkari A, Ijadi MH, Jafarzadeh M, Khadem P. Validation of a Farsi version of the early childhood oral health impact scale (F-ECOHIS). BMC Oral Health 2010; 10: 4

[http://dx.doi.org/10.1186/1472-6831-10-4] [PMID: 20367888]

[16] Peker K, Uysal Ö, Bermek G. Cross - cultural adaptation and preliminary validation of the Turkish version of the early childhood oral health impact scale among 5-6-year-old children. Health Qual Life Outcomes 2011; 9: 118 .

[http://dx.doi.org/10.1186/1477-7525-9-118] [PMID: 22192577]

[17] Scarpelli AC, Oliveira BH, Tesch FC, Leão AT, Pordeus IA, Paiva SM. Psychometric properties of the Brazilian version of the Early Childhood Oral Health Impact Scale (B-ECOHIS). BMC Oral Health 2011; 11: 19

[http://dx.doi.org/10.1186/1472-6831-11-19] [PMID: 21668959]

[18] Bordoni N, Ciaravino O, Zambrano O, Villena R, Beltran-Aguilar E, Squassi A. Early Childhood Oral Health Impact Scale (ECOHIS). Translation and validation in Spanish language. Acta Odontol Latinoam 2012; 25(3): 270-8.

[PMID: 23798073]

[19] Martins-Júnior PA, Ramos-Jorge J, Paiva SM, Marques LS, RamosJorge ML. Validations of the Brazilian version of the Early Childhood Oral Health Impact Scale (ECOHIS). Cad Saude Publica 2012; 28(2): 367-74.

[http://dx.doi.org/10.1590/S0102-311X2012000200015] [PMID: 22331162]

[20] Jankauskienė B, Narbutaitė J, Kubilius R, Gleiznys A. Adaptation and validation of the early childhood oral health impact scale in Lithuania. Stomatologija 2012; 14(4): 108-13. [PMID: 23455979]

[21] Masumo R, Bardsen A, Mashoto K, Åstrøm AN. Child- and family impacts of infants' oral conditions in Tanzania and Uganda-- a cross sectional study. BMC Res Notes 2012; 5: 538.

[http://dx.doi.org/10.1186/1756-0500-5-538] [PMID: 23016603]

[22] López Ramos RP, García Rupaya CR, Villena-Sarmiento R, Bordoni NE. Cross cultural adaptation and validation of the Early Childhood Health Impact Scale (ECOHIS) in Peruvian preschoolers. Acta Odontol Latinoam 2013; 26(2): 60-7. [PMID: 24303728]

[23] Hashim AN, Yusof ZY, Esa R. The Malay version of the Early Childhood Oral Health Impact Scale (Malay-ECOHIS)--assessing validity and reliability. Health Qual Life Outcomes 2015; 13: 190. [http://dx.doi.org/10.1186/s12955-015-0386-2] [PMID: 26607665]

[24] Bhat SG, Sivaram R. Psychometric properties of the Malayalam version of ECOHIS. J Indian Soc Pedod Prev Dent 2015; 33(3): 234-8. [http://dx.doi.org/10.4103/0970-4388.160398] [PMID: 26156279]

[25] Arrow P, Klobas E. Evaluation of the Early Childhood Oral Health Impact Scale in an Australian preschool child population. Aust Dent J 2015; 60(3): 375-81 [http://dx.doi.org/10.1111/adj.12236] [PMID: 25324159] 
[26] Farsi NJ, El-Housseiny AA, Farsi DJ, Farsi NM. Validation of the Arabic Version of the Early Childhood Oral Health Impact Scale (ECOHIS). BMC Oral Health 2017; 17(1): 60 [http://dx.doi.org/10.1186/s12903-017-0353-x] [PMID: 28245876]

[27] Zaror C, Atala-Acevedo C, Espinoza-Espinoza G, et al. Cross-cultural adaptation and psychometric evaluation of the early childhood oral health impact scale (ECOHIS) in chilean population. Health Qual Life Outcomes 2018; 16(1): 232.

[http://dx.doi.org/10.1186/s12955-018-1057-x] [PMID: 30554568]

[28] Taoufik K, Divaris K, Kavvadia K, Koletsi-Kounari H, Polychronopoulou A. Development of a Greek Oral health literacy measurement instrument: GROHL. BMC Oral Health 2020; 20(1): 14. [http://dx.doi.org/10.1186/s12903-020-1000-5] [PMID: 31941482]

[29] Anthoine E, Moret L, Regnault A, Sébille V, Hardouin JB. Sample size used to validate a scale: A review of publications on newlydeveloped patient reported outcomes measures. Health Qual Life Outcomes 2014; 12(1): 176

[http://dx.doi.org/10.1186/s12955-014-0176-2] [PMID: 25492701]

[30] Papagiannopoulou V, Oulis CJ, Papaioannou W, Antonogeorgos G, Yfantopoulos J. Validation of a Greek version of the oral health impact profile (OHIP-14) for use among adults. Health Qual Life Outcomes 2012; 10: 7.

[http://dx.doi.org/10.1186/1477-7525-10-7] [PMID: 22244162]

[31] World Health Organization. Oral health surveys: Basic methods WorldHealth Organization 4th ed. 1997.

[32] Guillemin F, Bombardier C, Beaton D. Cross-cultural adaptation of health-related quality of life measures: literature review and proposed guidelines. J Clin Epidemiol 1993; 46(12): 1417-32.

[http://dx.doi.org/10.1016/0895-4356(93)90142-N] [PMID: 8263569]

[33] D'agostino RB, Belanger A, D'Agostino RB Jr. A suggestion for using powerful and informative tests of normality. Am Stat 1990; 44(4): 316-21.

[34] Abanto J, Carvalho TS, Mendes FM, Wanderley MT, Bönecker M, Raggio DP. Impact of oral diseases and disorders on oral healthrelated quality of life of preschool children. Community Dent Oral Epidemiol 2011; 39(2): 105-14.

[http://dx.doi.org/10.1111/j.1600-0528.2010.00580.x]

[PMID: 21029148]

[35] Colak H, Dülgergil CT, Dalli M, Hamidi MM. Early childhood caries update: A review of causes, diagnoses, and treatments. J Nat Sci Biol Med 2013; 4(1): 29-38.

[http://dx.doi.org/10.4103/0976-9668.107257] [PMID: 23633832]

[36] Zaror C, Pardo Y, Espinoza-Espinoza G, et al. Assessing oral healthrelated quality of life in children and adolescents: A systematic review and standardized comparison of available instruments. Clin Oral Investig 2019; 23(1): 65-79.

[http://dx.doi.org/10.1007/s00784-018-2406-1] [PMID: 29569021]

[37] Locker D, Jokovic A, Clarke M. Assessing the responsiveness of measures of oral health-related quality of life. Community Dent Oral Epidemiol 2004; 32(1): 10-8.

[http://dx.doi.org/10.1111/j.1600-0528.2004.00114.x]

[PMID: 14961835]

\section{C) 2020 Taoufik et al.}

This is an open access article distributed under the terms of the Creative Commons Attribution 4.0 International Public License (CC-BY 4.0), a copy of which is available at: (https://creativecommons.org/licenses/by/4.0/legalcode). This license permits unrestricted use, distribution, and reproduction in any medium, provided the original author and source are credited. 